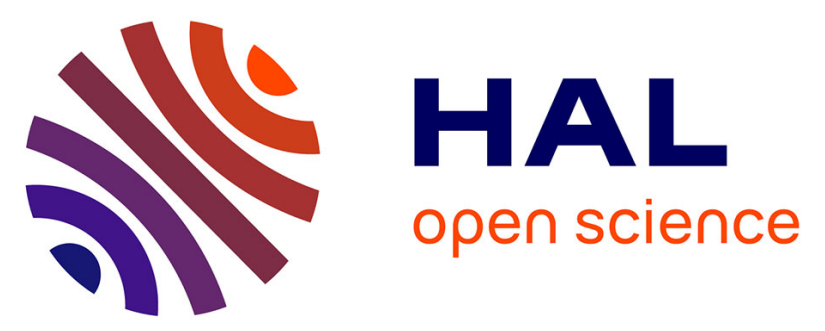

\title{
New method for clear day selection based on normalized least mean square algorithm
}

\author{
Mohamed Zaiani, Djelloul Djafer, Fatima Chouireb, Abdanour Irbah, \\ Mahfoud Hamidia
}

\section{- To cite this version:}

Mohamed Zaiani, Djelloul Djafer, Fatima Chouireb, Abdanour Irbah, Mahfoud Hamidia. New method for clear day selection based on normalized least mean square algorithm. Theoretical and Applied Climatology, 2020, 139 (3-4), pp.1505-1512. 10.1007/s00704-019-03059-5 . insu-02388761

\section{HAL Id: insu-02388761 https://hal-insu.archives-ouvertes.fr/insu-02388761}

Submitted on 2 Dec 2019

HAL is a multi-disciplinary open access archive for the deposit and dissemination of scientific research documents, whether they are published or not. The documents may come from teaching and research institutions in France or abroad, or from public or private research centers.
L'archive ouverte pluridisciplinaire HAL, est destinée au dépôt et à la diffusion de documents scientifiques de niveau recherche, publiés ou non, émanant des établissements d'enseignement et de recherche français ou étrangers, des laboratoires publics ou privés. 
1 New Method for Clear Day Selection Based on Normalized Least

2

\section{Mean Square Algorithm}

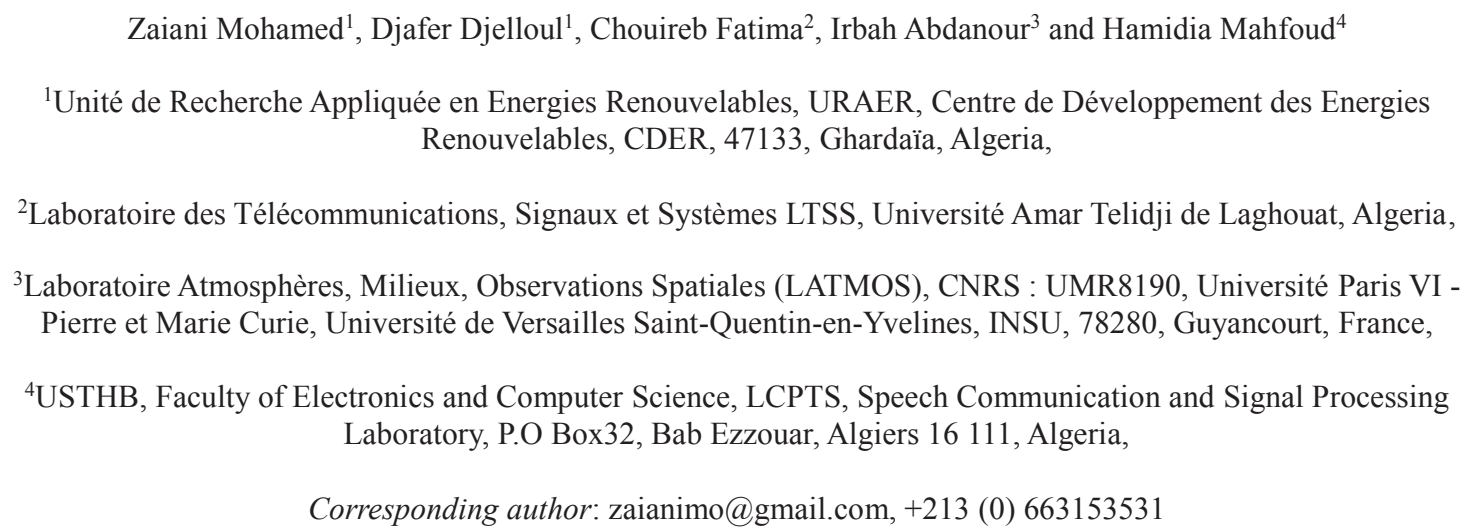

Abstract. A new method is proposed to select clear days from data sets of solar irradiation recorded with groundbased instruments. The knowledge of clear days for a given site is of prime importance both for the study of turbidity and for the validation of empirical models of Global Solar Radiation (GSR). Our innovative method is based on the Normalized Least Mean Square (NLMS) algorithm that estimates noise according to a GSR model. The developed method named Clear Day Selection Method (CDSM) is compared to the well-known clearness index criteria $\left(\mathrm{k}_{\mathrm{t}}\right)$ taking data collected at Tamanrasset in Algeria during the period 2005-2009. The root mean square error (rmse), the mean absolute percentage error (mape) and the dependence of model error (mbe) are considered for the comparison. A different number of clear days is found with both methods, with additionally a $\mathrm{k}_{\mathrm{t}}$ dependency for the clearness index criteria. The average values of rmse, mape and mbe between the daily average of the measured GSR and its estimate using a model are better in case of CDSM for the period 2005-2009. Indeed, we found $25.28 \mathrm{~W} / \mathrm{m}^{2}$, $4.61 \%$ and $2.09 \mathrm{~W} / \mathrm{m}^{2}$ respectively for CDSM and $42.48 \mathrm{~W} / \mathrm{m}^{2}, 7.63 \%$ and $-5.91 \mathrm{~W} / \mathrm{m}^{2}$ for the clearness index method with $\mathrm{k}_{\mathrm{t}}=0.7$. We also found that GSR of clear days is well correlated with the model in case of CDSM, which gives good confidence in our results.

Keywords clearness index, NLMS, adaptive algorithm, solar radiation 


\section{1- Introduction}

28 The Global Solar Radiation (GSR) is the total amount of solar radiation received by the Earth surface and 29 corresponds to the contribution of direct, diffuse and reflected solar radiation. Direct solar radiation is the 30 propagation of the beam directly through the atmosphere to the surface of the Earth, while diffuse solar radiation is 31 scattered in the atmosphere. Solar radiation is affected during its propagation through the atmosphere by atoms and 32 molecules (ozone, water vapor, carbon dioxide ...) as well as by liquid and solid aerosols dispersed or grouped in 33 clouds (Kaskaoutis 2008). Solar radiation measurements on the ground then depend on the site location. The 34 location must indeed be taken into account when we are interested in the quality and amount of solar radiation. GSR 35 is one of the most important parameters in solar energy designs and/or applications (Badescu et al. 2013; Reno et al. 36 2012). Analyzing solar radiation properties in a given location requires long-term data and both use of empirical, 37 semi-empirical or physical models and specific techniques such as neural networks (Senkal 2015; Mohandes 2012). 38 Many studies were carried out to estimate and/or predict solar radiation using available meteorological (air 39 temperature, relative humidity ...) and geographical (sunshine hours, latitude ...) parameters (Wong and Chow 2001; 40 Victor et al. 2016; Gueymard 2012). These models are needed to obtain the correct designs and outputs of solar 41 power plants in case of clear sky conditions. Selecting clear days from recorded datasets is the first step in modelling 42 solar radiation under these conditions. The clearness index method, based essentially on the calculation of a 43 parameter $k_{t}$ related to measured solar radiation, is widely used for this purpose (Alves et al. 2013; Khem et al. 44 2012; Mellit et al. 2008). Authors then sorted day types using the $k_{t}$ parameter according to their own criteria. The 45 sky is, for some, clear when its value is between 0.65 and 1 , partly cloudy when $0.3 \leq k_{t} \leq 0.65$ and cloudy if $0 \leq$ $46 k_{t} \leq 0.3$ (Gueymard 2012; Alves et al. 2013). For other authors, a clear sky is when $0.5 \leq k_{t} \leq 0.85$ (Bendt et al. 47 1981; Ahmed et al. 2008), higher than 0.6 (Reindl et al. 1990) or 0.7 (Li and Lam 2001; Li et al. 2004). Iqbal considers that the sky is clear when $k_{t}$ is between 0.7 and 0.9 (Iqbal 1983). $k_{t}$ also varies in time (Serban 2009) and depends on regions. Its value in most tropical regions is between 0.68 and 0.75 for a clear sky (Ndilemeni et al. 2013). We see clearly with this short bibliographic that there is a great disparity in the definition of a clear sky using 51 this parameter and there is no clear method for its estimation. The choice of its value can be crucial to distinguish 52 clear days from turbid ones. A wrong choice will affect mainly the number of clear and turbid days in a dataset 
54 the issue of the clearness index choice led us to develop a new method for classifying clear and turbid days. The 55 method is based on the Normalized Least Mean Square algorithm (Sharma and Mehra 2016; Dixit and Nagaria 56 2017), which is an adaptive algorithm based on minimization of the norm of differences between estimate and real 57 signal. This method is often used in signal processing for noise identification or cancellation (Sahu and Sinha 2015; 58 Gupta and Bansal 2016) and is therefore suited for GSR measurements. Indeed, its perturbations are due to solar 59 radiation propagation through the atmosphere and are well assimilated as noise in our process. In this work, we first 60 present the clearness index algorithm used to distinguish clear and turbid days, and then introduce CDSM, the 61 NLMS method for Clear Days Selection. A comparison of these methods will then be made and the results 62 discussed.

\section{2- The Clearness index method}

64 The clearness index $k_{t}$ was introduced by Liu and Jordan to quantify stochastic property conditions for a given site 65 (Liu and Jordan 1960). Interval values for $k_{t}$ are taken to separate clear and turbid days but are often site dependent 66 (see Section 1), which leads to misinterpretation of the results, especially when authors compare and study empirical 67 models. The clearness index $k_{t}$ is defined over time $t$ as the ratio between the terrestrial global solar radiation $68 \operatorname{GSR}(t)$ on a horizontal surface and the extraterrestrial one $G_{0}$ :

70 where $G_{0}$ in $W / m^{2}$ is given by:

$$
G_{0}=I_{S} c *\left[1+0,0033 * \cos \left(\frac{360 * N}{365}\right)\right] *(\cos \phi * \cos \delta * \cos \omega * \sin \phi * \sin \omega)
$$

$72 I_{s c}$ is the Total Solar Irradiance (TSI) equal to $1361 \mathrm{~W} / \mathrm{m}^{2}$ (Myhre et al. 2013) and $\mathrm{N}$ the day number in the year 73 ( $\mathrm{N}=1$ is the first day in the year and $\mathrm{N}=365$ the last one). $\phi, \delta$ and $\omega$ are respectively the latitude of the location, the 74 solar declination angle and the hour angle at sunrise in degrees.

75 An algorithm based on the instantaneous clearness index was first developed for our work to automatically select 76 days from a huge dataset. The main steps of the algorithm are:

77 - Selection of $\operatorname{GSR}(t)$ records of a given day where the Sun elevation is higher than $10^{\circ}$. 
This condition is only intended to prevent the presence of haze early in the morning or late in the afternoon. This could lead to considering a clear day as not being one.

- Calculation of the extraterrestrial solar radiation $G_{0}$ for the same day.

81 - Calculation of the instantaneous clearness index $k_{t}$ between sunrise and sunset using Equation 1.

\section{3- Normalized Least Mean Square Method for Clear Days Selection}

83 We present in this section the Normalized Least Mean Square (NLMS) algorithm and then how we use it to select 84 clear days from data sets.

\section{3-1. The NLMS algorithm}

86 The Least Mean Square (LMS) algorithm was first developed by Widrow and Hoff in 1959 for speech recognition 87 applications. It is today one of the most widely used algorithms in adaptive filtering mainly due to its efficiency and computational simplicity. LMS algorithms are a class of adaptive filters used to generate a desired filter that produces least mean squares of the error signal i.e. difference between desired and real signal. The algorithm starts 90 by assuming small weights (zero in most cases) at each step and finding the gradient of the estimated error. Weights 91 are then updated according to the following equation (Dixit and Nagaria 2017):

$$
w_{n+1}=w_{n}+\alpha \times e(n) \times x(n)
$$

93 Here $x(n)$ is an input vector with $L$ delayed values in time. $\mathrm{w}(\mathrm{n})=\left[\mathrm{w}_{0}(\mathrm{n}) \mathrm{w}_{1}(\mathrm{n}) \mathrm{w}_{2}(\mathrm{n}) \ldots \mathrm{w}_{\mathrm{L}-1}(\mathrm{n})\right]^{\mathrm{T}}$ is a vector with $L$ 94 components containing the tap weight coefficients of the adaptive FIR (Finite Impulse Response) filter at time $n$, $95 e(n)$ is the estimated filter error at $n$ and the subscript $T$ stands for transpose operator. The $\alpha$ parameter is known as 96 the step size parameter and is a small positive constant. This parameter controls the influence of the updating factor. 97 Selection of a suitable value of $\alpha$ is imperative for the performance of the LMS algorithm. The time taken by the 98 adaptive filter to converge into the optimal solution will be too long if its value is too small. The adaptive filter 99 becomes unstable if $\alpha$ is too large and its output diverges (Sharma and Mehra 2016; Dixit and Nagaria 2017). The stability condition of the LMS algorithm is $0<\alpha<2 / \lambda_{\max }$, where $\lambda_{\max }$ is is the largest eigenvalue of the autocorrelation matrix of the input signal $x(n)$. The main disadvantage of LMS algorithm is the fixed step size 
parameter for every iteration. This requires knowledge of the input signal statistics prior to starting the adaptive filtering operation. The NLMS algorithm is an extension of the LMS one, which by passes this issue by calculating the maximum step size value. This step size is proportional to the inverse of the total expected energy of instantaneous coefficients of the input vector $x(n)$. The recursion formula for NLMS algorithm is given by (Hamidia and Amrouche 2016):

$$
w(n+1)=w(n)+\frac{\mu}{\epsilon+x^{T}(n) \times x(n)} \times e(n) \times x(n)
$$

where $0<\mu<2$ is the adaptation step size of NLMS and $\epsilon>0$ is a regularization constant used to avoid division by zero.

The NLMS algorithm is implemented according to the following steps:

- The output signal $y(n)$ of the adaptive filter is calculated by:

$$
y(n)=w^{T}(n) \times x(n)
$$

- $\quad$ The estimated filter error signal $e(n)$ at step (n) is computed as the difference between the desired signal and the filter output:

$$
e(n)=d(n)-y(n)
$$

117 Basic modules of an adaptive filter are shown in Figure 1 (Dixit and Nagaria 2017). The output of the adaptive filter 118 and the desired response are processed to assess its quality with respect to requirements of a particular application. 119 This module generates the filter output using input signal measurements. The filtering structure is linear or nonlinear 120 according to the designer and its parameters are adjusted by the adaptive algorithm. 


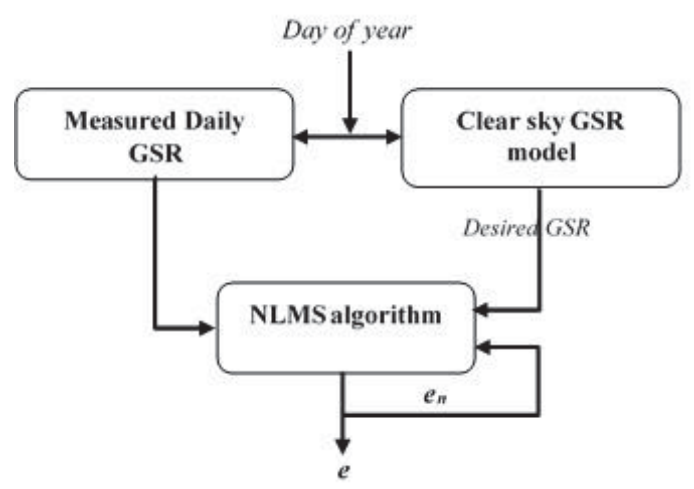

Figure 2. Flowchart of CDSM

\section{3-2. The CDSM algorithm}

Our proposed method for selecting clear days present in dataset is based on the NLMS algorithm and any parametric GSR model. The Capderou model has been used in this work (Capderou 1987). This parametric model uses the Linke turbidity to compute the global, direct and diffuse components of clear sky solar radiation. The main idea of the method is to compare estimated GSR with measurements i.e. GSR resulting from adaptive filtering when taking GSR measurements as input are compared to GSR model of clear sky. CDSM is summarized by the following steps (Figure 2) (Quadri et al. 2017):
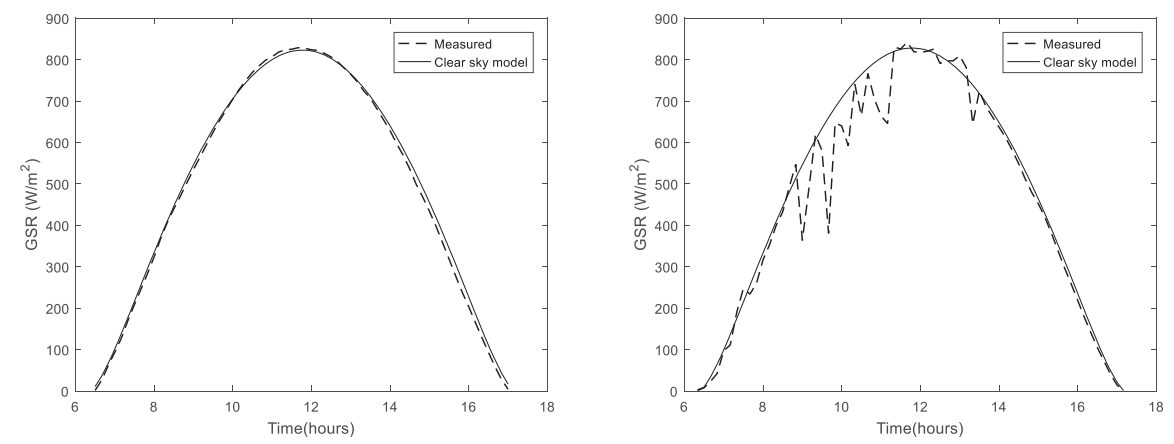

Figure 3. Examples of daily recorded GSR (dashed line) superposed to the clear sky model (full line).

Each daily GSR is fitted with a clear sky GSR model.

130 - The measured GSR is subjected to a parameterized FIR filtering with $w_{n}$ coefficients (see previous section): 
a sample of the modeled GSR is obtained.

The estimated filter error between samples of modelled GSR and clear sky GSR model is calculated.

- The obtained estimated filter error is used to calculate the next step that is used to readjust FIR filter coefficients $\left(w_{n+1}\right)$

- Steps 1-4 are considered for all samples of the measured GSR
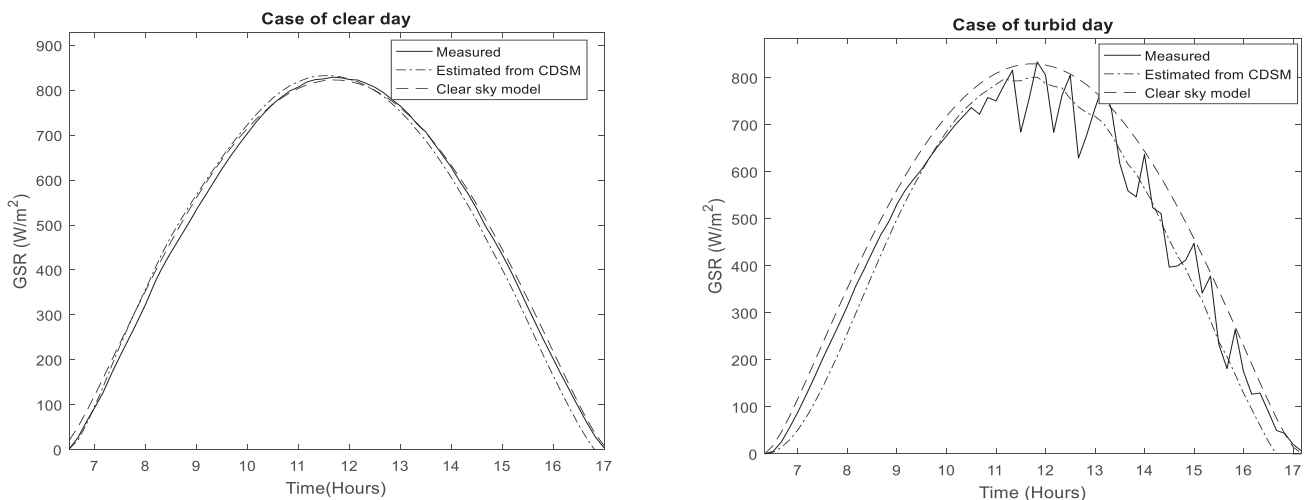

Figure 4. CDSM behavior in case of a clear (left) and a turbid day (right).

136 Figure 3 plots an example of daily measured GSR (dashed line) superposed to the clear sky GSR model (full line) 137 for both clear (left plot) and turbid (right plot) days. Figure 4 shows CDSM behavior to estimate GSR in case of 138 clear (left plot) and turbid days (right plot). The adaptive filter takes a measured GSR as input and produces a 139 modeled GSR by recursively adjusting the filter parameters to handle the disturbances present in the GSR 140 measurement. Figure 5 plots the estimated filter error obtained when CDSM is run on data of Figure 4. We see that 141 the method allows having a modelled GSR more or less disturbed according to the data considered. It will be close 142 to the GSR model when the estimated filter error is small i.e. the case of clear days. We will consider in our study 143 that clear days correspond to the estimated filter error less than $20 \mathrm{~W} / \mathrm{m}^{2}$; otherwise they are considered as turbid. 

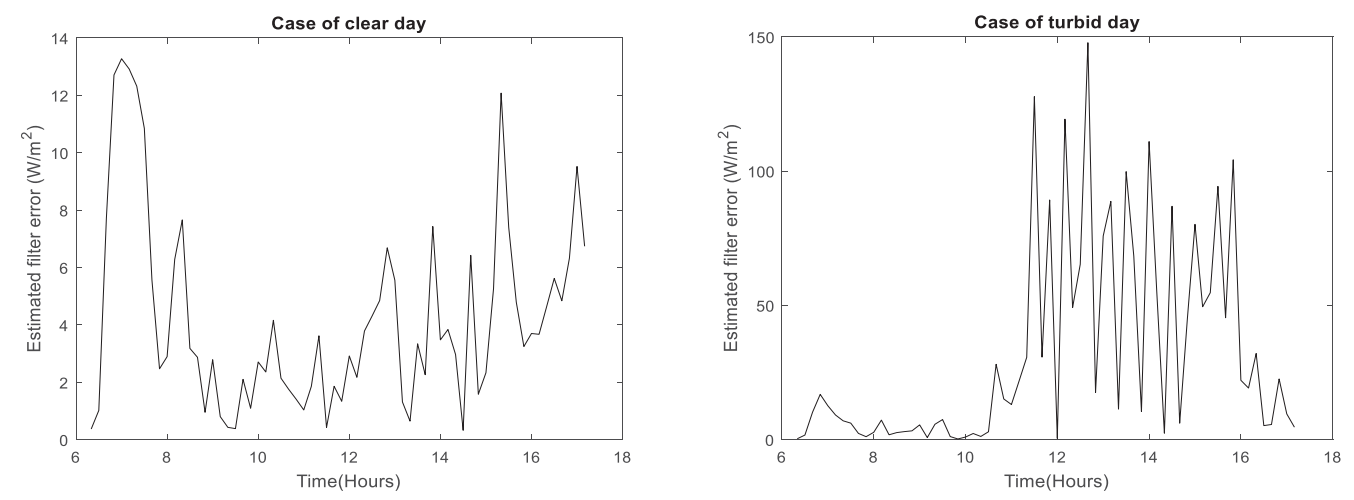

Figure 5. Estimated filter error of the GSR estimate for a clear (left) and a turbid day (right).

\section{4- Comparison of clear day selection methods. Results and discussion.}

145 We use GSR data recorded from 2005 to 2009 in southern Algeria to compare the efficiency of CDSM relative to 146 other methods. Let us first present the data set.

\section{4-1. Data set of solar radiation}

148 Data used in this work were collected at the Regional Meteorological Center (Direction Météo Régional Sud, Office 149 National de la Météorologie, Algeria) at Tamanrasset $\left(22.79^{\circ} \mathrm{N}, 5.53^{\circ} \mathrm{E}, 1377 \mathrm{~m}\right.$ a.s.l.) in southern Algeria between 1502005 and 2009. Instruments and methods for data collection are the same as those described in detail by Djafer and 151 Irbah (Djafer and Irbah 2013). The main difference is that the three components of solar radiation are recorded every 152 minute at Tamanrasset together with temperature, humidity and pressure. Instruments that measure direct, global and 153 diffuse solar radiation components are EKO type instruments (http://eko-eu.com/) (see Figure 6). They are cleaned 154 two to three times a week depending on weather conditions and calibrated every three years. Data were calibrated 155 with the TSI of $1367 \mathrm{~W} / \mathrm{m}^{2}$ since it was the current value at this period $(2005-2009)$. A correction factor is applied 156 to the data since the TSI of $1361 \mathrm{~W} / \mathrm{m}^{2}$ is now adopted. This factor is the ratio between current and previous TSI. 


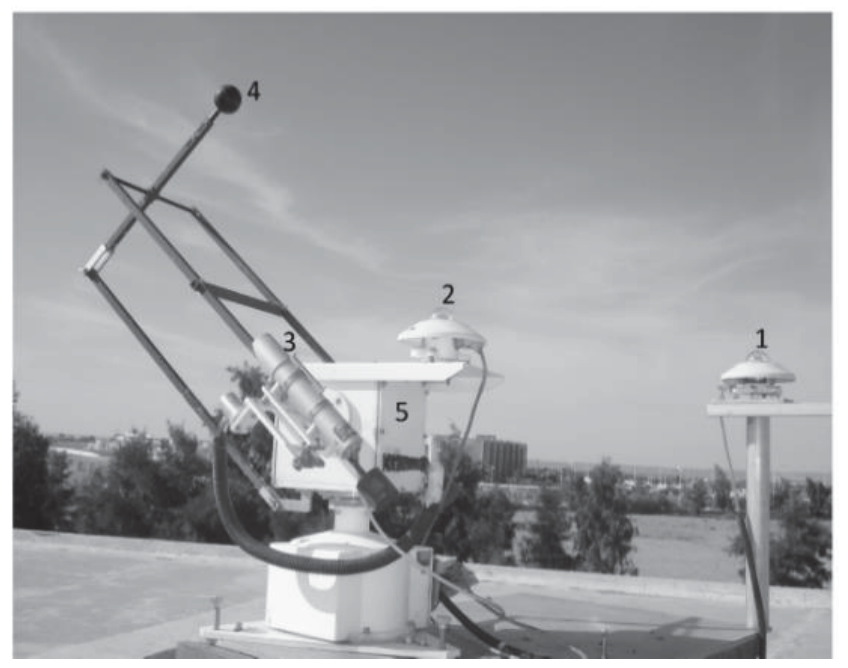

Figure 6. Radiometric station for measuring global, direct and diffuse solar radiation: (1) Pyranometer for measuring the global solar irradiance. (2) Pyranometer for measuring the diffuse. (3) Pyrheliometer for measuring the direct solar irradiance, (4) Shaded pyranometer. (5) The 2-axis solar tracker.

\section{4-2. Results and discussion}

158 We used the five years of GSR measurements (see section 4.1) and determined clear days present in the data set with 159 the clearness index, wavelet based method (Djafer et al. 2017) and CDSM. Results are given in Table 1 and plotted 160 in Figure 7 where error bars are one standard deviation. $k_{t}$ values widely used in the literature to select clear days 161 were considered for the comparison, that is $0.5 \leq k_{t} \leq 0.8$.

Table 1. Number of clear days per year selected with different methods

\begin{tabular}{cccccc}
\hline Years & 2005 & 2006 & 2007 & 2008 & 2009 \\
\hline Wavelet method & 59 & 30 & 65 & 98 & 24 \\
\hline CDSM & 136 & 133 & 173 & 173 & 120 \\
\hline $\boldsymbol{k}_{\boldsymbol{t}}=\mathbf{0 . 5}$ & 303 & 316 & 319 & 322 & 305 \\
\hline $\boldsymbol{k}_{\boldsymbol{t}}=\mathbf{0 . 6}$ & 244 & 254 & 279 & 274 & 254 \\
\hline $\boldsymbol{k}_{\boldsymbol{t}}=\mathbf{0 . 7}$ & 114 & 133 & 158 & 170 & 139 \\
$\boldsymbol{k}_{\boldsymbol{t}}=\mathbf{0 . 8}$ & 2 & 7 & 6 & 14 & 7 \\
\hline
\end{tabular}



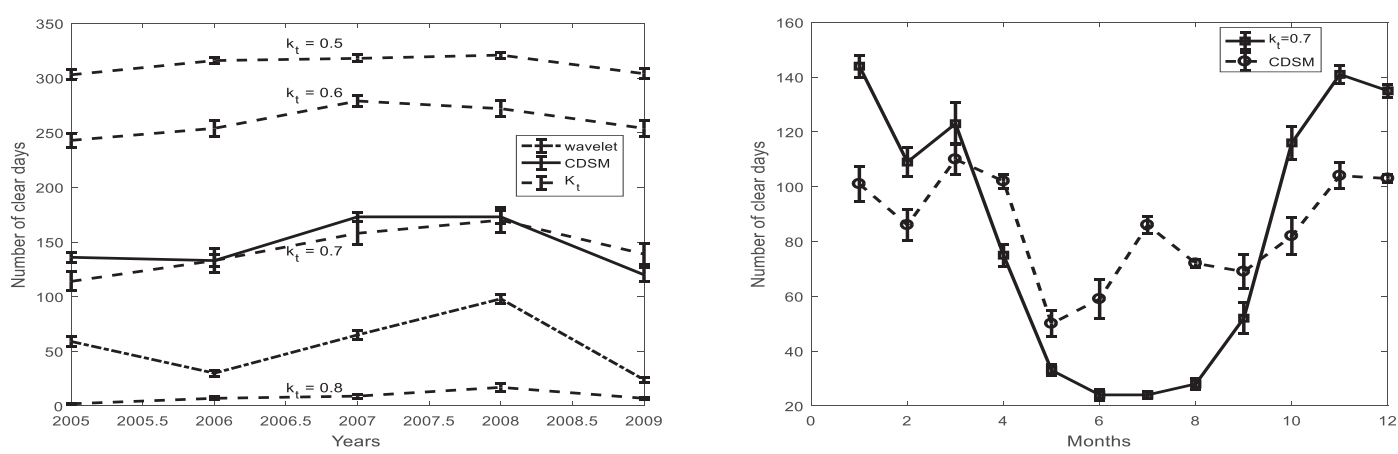

Figure 7. Number of clear days selected with the different methods: number per year (left) and per month (right).

162 We observe in the left plot of Figure 7 that the number of clear days per year obtained with CDSM is close to what is found with $k_{t}=0.7$. Lower $k_{t}$ values overestimate the number of clear days while higher ones underestimate it. The wavelet method seems to underestimates the yearly number of clear days due to excessive constraints on GSR disturbances when setting the selection threshold. The three methods show the same trend of the yearly number of clear days with a maximum around 2008. If we look at the monthly values of clear days computed over the period 2005-2009, we observe a difference between CDSM results and those obtained with the clearness index with $k_{t}=$ 0.7 (see right plot of Figure 7). Curves have similar shapes but the number range for the clearness method is large relative to the CDSM one. There is quasi no clear days found for months between May and August with $k_{t}=0.7$ leading to suppose that its value needs to be adjusted during processing as reported in section 1 . We note that the number of clear days at Tamanrasset is lower during the months of May and September-October compared to the others.

Finally, we compared GSR of clear days obtained with both $k_{t}=0.7$ and CDSM to those estimated by the model described in Zaiani et al. (2017). This parametric model used Artificial Neural Network to estimate GSR of a given clear day. We used several parameters to quantify the comparison among which are the root mean square error (rmse), the normalized root mean square error (nrmse), the mean absolute percentage error (mape), the dependence of model error (mbe) and the normalized dependence of model error (nmbe). Comparison results are given in Table 2. We note that the model fits better the measured GSR of clear days determined with CDSM. Indeed, we have a mean $R^{2}$ of 0.97 , an rmse of $25.28 \mathrm{~W} / \mathrm{m}^{2}$, an mbe of $2.09 \mathrm{~W} / \mathrm{m}^{2}$ and a mape of $4.16 \%$ while we have a mean $R^{2}$ of 
0.94, an rmse of $42.58 \mathrm{~W} / \mathrm{m}^{2}$, an mbe of $1.97 \mathrm{~W} / \mathrm{m}^{2}$ and a mape of $7.55 \%$ for the clearness index method. Figure 8 plots the correlation between daily average measured GSR of clear days selected with CDSM (left plot) and with the clearness index method $\left(k_{t}=0.7\right)$ (right plot) versus daily average calculated GSR. We note that GSR of clear days selected with CDSM are very well correlated with the model compared to what we obtain with the clearness index method. The correlation factor is 0.99 for CDSM and 0.95 using $k_{t}$ criteria. We may conclude when looking at this plot that we can be confident in the results obtained from CDSM.

Table 2. Annual average errors between measured and calculated GSR

\begin{tabular}{|c|c|c|c|c|c|c|c|}
\hline Method & Errors & 2005 & 2006 & 2007 & 2008 & 2009 & Average \\
\hline \multirow{6}{*}{ CDSM } & $\operatorname{rmse}\left(W / m^{2}\right)$ & 24.63 & 24.72 & 26.75 & 25.51 & 24.79 & 25.28 \\
\hline & nrmse (\%) & 3.63 & 3.64 & 4.43 & 4.19 & 3.54 & 3.88 \\
\hline & mape $(\%)$ & 4.26 & 4.27 & 5.33 & 5.01 & 4.20 & 4.16 \\
\hline & mbe $\left(W / m^{2}\right)$ & 2.01 & 2.00 & 2.25 & 2.15 & 2.05 & 2.09 \\
\hline & nmbe $(\%)$ & 0.27 & 0.27 & 0.59 & 0.55 & 0.27 & 0.39 \\
\hline & $R^{2}$ & 0.99 & 0.99 & 0.95 & 0.95 & 0.99 & 0.97 \\
\hline \multirow{6}{*}{$\mathbf{k}_{\mathrm{t}}$} & $\operatorname{rmse}\left(W / m^{2}\right)$ & 42.00 & 41.45 & 44.11 & 37.47 & 47.84 & 42.58 \\
\hline & nrmse (\%) & 6.92 & 6.60 & 7.07 & 5.89 & 7.38 & 6.77 \\
\hline & mape $(\%)$ & 7.56 & 7.29 & 7.82 & 6.68 & 8.40 & 7.55 \\
\hline & mbe $\left(W / m^{2}\right)$ & 1.24 & 2.97 & 2.89 & 2.54 & -0.2 & 1.97 \\
\hline & nmbe $(\%)$ & 0.11 & 0.43 & 0.40 & 0.35 & 0.03 & 0.27 \\
\hline & $R^{2}$ & 0.94 & 0.94 & 0.94 & 0.95 & 0.93 & 0.94 \\
\hline
\end{tabular}
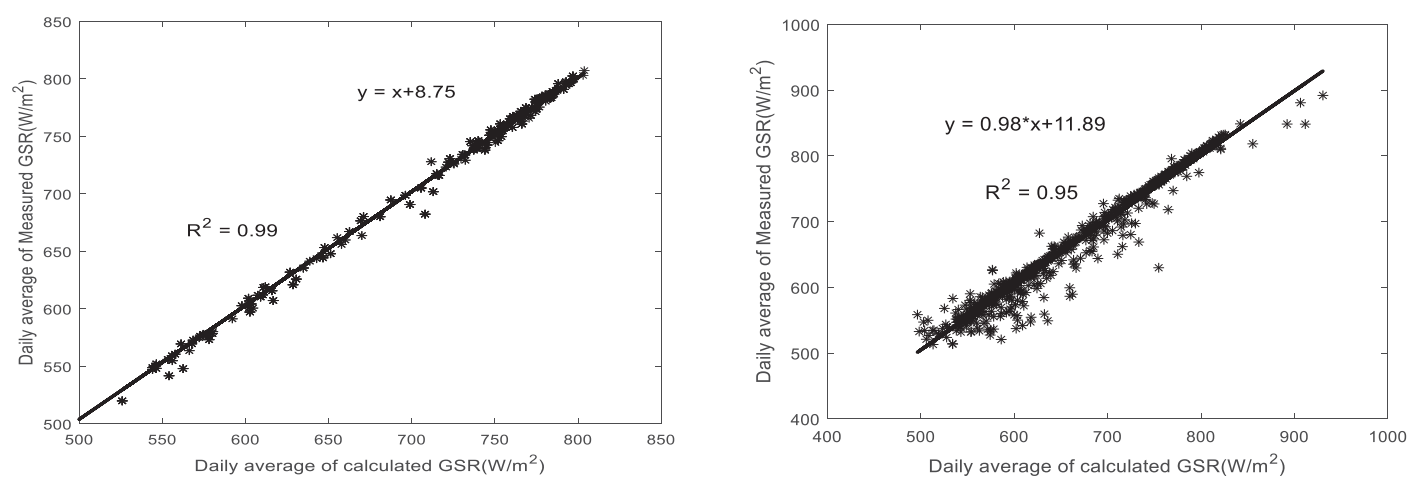

187 Figure 8. Correlation between daily average of calculated and measured GSR obtained with CDSM (left) and with the clearness index with $\mathrm{k}_{\mathrm{t}}=0.7$ (right) . 


\section{5- Conclusion}

A new method to select clear days in data sets of solar radiation is presented in this work. This method we denoted CDSM, is based on NLMS algorithm. We first compared CDSM to the clearness index method taking the most used value $k_{t}=0.7$ and found that our method gives a higher number of clear days when using the same data set. We took a data set of 5 years of solar radiation measurements collected at the Tamanrasset ONM. We then validated CDSM using the clear days selected by both methods to model daily GSR. The analysis of the difference between GSR of the clear days selected with CDSM and calculated for these days with the model shows a very good agreement. We found that yearly values vary between (i) 4.20 and $5.33 \%$ for mape, (ii) 0.95 and 0.99 for $R^{2}$, (iii) 24.63 and $26.75 \mathrm{~W} / \mathrm{m}^{2}$ for rmse and (iv) 2.00 and $2.25 \mathrm{~W} / \mathrm{m}^{2}$ for mbe. Finally, we performed a comparison of daily average GSR of clear days obtained with both CDSM and the clearness index method with $k_{t}=0.7$ and those estimated with the model. We found that the GSR of clear days selected with CDSM are better correlated with the model than those obtained with the clearness index method. The correlation coefficient is 0.99 for CDSM and 0.95 using $k_{t}$ criteria. We can emphasize that our method was developed using daily measured GSR but may also be adapted to detect clear and turbid short periods in measurements. These short periods are very useful for studying the environment and regional frequency of clouds. In addition, knowledge of the occurrence of clear days on a site also has many other interests. This is particularly the case before any photovoltaic or thermal installation for which solar radiometric measurements over a longer or shorter period are necessary. Our work is then very useful to give the relevant information on the number of clear days for a given site and consequently to predict the energy that these facilities will produce in this region.

\section{References}

Ahmed MA, Ahmad F, Akhtar MW (2008) Estimation of Global and Diffuse Solar Radiation for Hyderabad, Sindh, Pakistan. Journal of Basic and Applied Sciences 5: 73-77

Alves MdC, Sanches L, Nogueira JDS, Silva VAM (2013) Effects of Sky Conditions Measured by the Clearness Index on the Estimation of Solar Radiation Using a Digital Elevation Model. Atmospheric and Climate Sciences 3: 618-626 
Badescu V, and Gueymard CA, Cheval S, Oprea C, Baciu M, Dumitrescu A, Iacobescu F, Milos I, Rada C (2013) Accuracy analysis for fifty-four clear-sky solar radiation models using routine hourly global irradiance measurements in Romania. Renewable Energy 55: 85-103

Bendt P, Collares-Pereira M, Rabl A (1981) The frequency distribution of daily insolation values. Solar Energy 27: $1-5$

Capderou M (1987) Modèles Théoriques et Expérimentaux. Atlas Solaire de l'Algérie, Tome 1, Vol. 1 et 2, Office des Publications Universitaires, Algérie

Dixit S, Nagaria D (2017) LMS Adaptive Filters for Noise Cancellation: A Review. International Journal of Electrical and Computer Engineering (IJECE) 7: 25202529

Djafer D, Irbah A (2013) Estimation of atmospheric turbidity over Ghardaia city. Atmospheric Research 128: 78-84

Djafer D, Irbah A, Zaiani M (2017) Identification of clear days from solar irradiance observations using a new method based on the wavelet transform. Renewable Energy 101: 347- 355

Gueymard CA (2012) Clear-sky irradiance predictions for solar resource mapping and large-scale applications: Improved validation methodology and detailed performance analysis of 18 broadband radiative models. Solar Energy 86: 2145-2169

Gupta N, Bansal P (2016) Evaluation of Noise Cancellation Using LMS and NLMS Algorithm. International Journal of Scientific \& Technology Research 5: 69-72

Hadei SA, lotfizad M (2010) A Family of Adaptive Filter Algorithms in Noise Cancellation for Speech Enhancement. International Journal of Computer and Electrical Engineering, Vol. 2, No. 2

Hamidia M, Amrouche A (2016) Improved variable step-size NLMS adaptive filtering algorithm for acoustic echo cancellation. Digital Signal Processing 49: 44-55

Iqbal M (1983) An Introduction to Solar Radiation. Academic Press, Toronto

Kaskaoutis DG, Kambezidis HD (2008) Comparison of the Angstrom parameters retrieval in different spectral ranges with the use of different techniques. Meteorol Atmos Phys 99: 233-246

Khem NP, Binod KB, Balkrishna S, Berit K (2012) Estimation of Global Solar Radiation Using Clearness Index and 
Cloud Transmittance Factor at Trans-Himalayan Region in Nepal. Energy and Power Engineering 4: 415421

Li DHW, Lam JC (2001) An analysis of climate parameters and sky condition classifications. Building and Environment 36: 435-445

Li DHW, Lau CCS, Lam JC (2004) Overcat sky conditions and luminance distribution in Hong Kong. Building and Environment 39: 101-108

Liu BYH, Jordan RC (1960) The interrelationship and characteristic distribution of direct, diffuse and total solar radiation. Solar Energy 4: 1-19

Mellit A, Kalogirou SA, Shaari S, Salhi H, Hadj Arab A (2008) Methodology for predicting sequences of mean monthly clearness index and daily solar radiation data in remote areas: Application for sizing a stand-alone PV system. Renewable Energy 33: 1570-1590

Mohandes MA (2012) Modeling global solar radiation using Particle Swarm Optimization (PSO). Solar Energy 86: $3137-3145$

Myhre G, Shindell D, Bréon FM, Collins W, Fuglestvedt J, Huang J, Koch D, Lamarque JF, Lee D, Mendoza B, Nakajima T, Robock A, Stephens G, Takemura T and Zhang H (2013) Anthropogenic and Natural Radiative Forcing. In: Climate Change 2013: The Physical Science Basis. Contribution of Working Group I to the Fifth Assessment Report of the Intergovernmental Panel on Climate Change.

Ndilemeni CC, Momoh M, Akande JO (2013) Evaluation of clearness index of Sokoto Using Estimated Global Solar Radiation. Journal of Environmental Science, Toxicology and Food Technology 5: 51-54

Okogbue EC, Adedokunb JA, Holmgrenc B (2009) Review Hourly and daily clearness index and diffuse fraction at a tropical station, Ile-Ife, Nigeria. International Journal of Climatology 29: 1035-1047

Quadri A, Manesh MR, Kaabouch N (2017) Noise Cancellation in Cognitive Radio Systems: A Performance Comparison of Evolutionary Algorithms. IEEE 7th Annual Computing and Communication Workshop and Conference (CCWC)

Radhika C, Ramkiran DS, Khan H, Usha M, Madhav BTP, Srinivas PK, Ganesh GV (2011) Adaptive Algorithms for 
Acoustic Echo Cancellation in Speech Processing. Ijrras $7: 38-42$

Reindl DT, Beckman WA, Duffie JA (1990) Diffuse fraction correlation. Solar Energy 45: 1-7

Reno MJ, Hansen CW, Stein JS (2012) Global Horizontal Irradiance Clear Sky Models: Implementation and Analysis. Sandia National Laboratories SAND2012-2389

Sahu K, Sinha R (2015) Normalized Least Mean Square (Nlms) Adaptive Filter for Noise Cancellation. International Journal of Proresses in Engineering, Management, Science and Humanities 1: 49-53

Senkal O (2015) Solar radiation and precipitable water modeling for Turkey using artificial neural networks. Meteorol Atmos Phys. DOI 10.1007/s00703-015-0372-6

Serban C (2009) Estimating Clear Sky Solar Global Radiation Using Clearness Index, for Brasov Urban Area. International Conference on Maritime and Naval Science and Engineering, ISSN: 1792-4707

Sharma L, Mehra R (2016) Adaptive Noise Cancellation using Modified Normalized Least Mean Square Algorithm. International Journal of Engineering Trends and Technology (IJETT) 34: 215-219

Victor HQ, Almorox J, Mirzakhayot I, Saito L (2016) Empirical models for estimating daily global solar radiation in Yucatán Peninsula, Mexico. Energy Conversion and Management 110: 448-456

Wong LT, Chow WK (2001) Solar radiation model. Applied Energy 69: 191-224

Zaiani M, Djafer D, Chouireb F (2017) New Approach to Establish a Clear Sky Global Solar Irradiance Model. International Journal of Renewable Energy Research 7: 1454-1462 